\title{
The Immunoreactivity of Calbindin on Cerebellum Cortex and Hippocampus of Mice Brain after One Week Exposure to Radiofrequency Radiation
}

\author{
Bijay Aryal \\ Department of Clinical Pharmacology and Therapeutics, Gandaki Medical College, Pokhara
}

\section{Correspondence}

Dr. Bijay Aryal.

Department of Clinical

Pharmacology and

Therapeutics, Gandaki Medical

College.

Pokhara, Nepal

\section{Email:}

phrbijayaryal@gmail.com

DOI: http://dx.doi.org/10.3126/ jemsn.v13i3.17905

Orcid ID: orcid.org/0000-0002 $-6449-5837$

Article received: June $28^{\text {th }} 2017$ Article accepted: Oct $9^{\text {th }} 2017$

\begin{abstract}
Background \& Objectives: Radiofrequency radiation affects the calcium permeability and accordingly this induces pathophysiological changes in the brain and its subsequent output in the brain as tumor genesis, neural degeneration, and cognition or behavior changes. Hence, we investigated the effects of radiofrequency (RF) radiation on calcium binding proteins, reactive gliosis, and tumor genesis in mouse brain. Materials \& Methods: Mice were exposed to radiofrequency radiation in the cage chamber with average specific absorption rate (SAR) of 1.6 $\mathrm{W} / \mathrm{kg}$ and $4.0 \mathrm{~W} / \mathrm{Kg}$ for one hour per day for five days. For histochemical studies, radiofrequency exposed brains were compared with sham control using calbindin D-28k antibody. Results: The immunoreactivity of calbindin D-28k, a marker for calcium homeostasis was found to increase in dose-response manner in hippocampus and cerebellar cortex. Conclusion: The short-term exposure to $835 \mathrm{MHz}$ RF could induce disruption of calcium homeostasis and resulting neurobehavioral changes or brain tumor.
\end{abstract}

Key words: Catheter Calbindin; Cerebellar Cortex; D-28Kand Radiofrequency radiation

Citation: Aryal B. The Immunoreactivity of Calbindin on Cerebellum Cortex and Hippocampus of Mice Brain after One Week Exposure to Radiofrequency Radiation. JCMS Nepal. 2017;13(3):340-4.

\section{INTRODUCTION}

Environmental exposure to anthropogenic electromagnetic fields and radiation (EMFs) has steadily increased throughout the last decades. Nowadays, everyone is exposed to a complex mix of EMFs at both home and work, from generation and transmission of electricity, from domestic appliances and industrial plant, and from telecommunications and broadcasting. Although there have been numerous undoubted benefits from the widespread use of electricity, there is a significant community concern that exposure to EMFs at even low levels could entail detrimental consequences on human health. ${ }^{1}$ In addition, a recent increase in popularity of personal communications has heightened the public awareness of radiofrequency (RF) radiation and generated rumors that the radiation from mobile telephone handsets and base stations are responsible for causing headaches, loss of memory, and brain tumors. A large number of laboratory experiments have been performed in response to this concern to discover the biological effects of EMF. ${ }^{2}$ Many biological endpoints have been examined using various frequencies and a mixture of different field strengths. ${ }^{3}$

Alteration of cognitive and physiological function of brain upon exposure to mobile phone frequency radiation has been reported by several electrophysiological studies. ${ }^{4}$ In these studies, RF exposures could induce measurable changes in electrical activity of human brain, particularly in the alpha frequency band ( 8 to $13 \mathrm{~Hz}$ ) over posterior regions of the scalp. Furthermore, rats exposed to RF showed neuronal damage in the cortex, hippocampus, and basal ganglia, while it was not reproduced by others. ${ }^{5,6}$ Therefore, there are a number of points to consider regarding whether RF 
radiation affects the calcium permeability and accordingly this induces pathophysiological changes in the brain and its subsequent output in the brain as tumor genesis, neural degeneration, and cognition or behavior changes. Hence, the present study investigated the effects of RF radiation on calcium binding proteins and brain tumor marker in mouse brain after one exposure using immunohistochemistry and immunofluoresence approaches.

\section{MATERIALS AND METHODS Animals:}

Six weeks 20 to $30 \mathrm{gm}$ male mice were used for the experiment. Mice were acclimated for one week. Upon arrival, animals were randomized and housed six per cage in condition of 20 to $25^{\circ} \mathrm{C}$ and $\mathrm{RH} 45$ to $50 \%$. Food and water were supplied ad libitum. All animal procedures were performed according to the Institutional animal care and research center of Dankook University and were approved by the IBST committee of Dankook University Medical Center. Before conducting the study, mice were categorized into three groups: low RF group A (1.6 $\mathrm{w} / \mathrm{kg}, \mathrm{N}=6)$, high RF group $\mathrm{B}(4.0 \mathrm{w} / \mathrm{kg}, \mathrm{N}=6)$, and sham control group $\mathrm{C}(0 \mathrm{w} / \mathrm{kg}, \mathrm{N}=6)$.

\section{Mobile phone wave radiation apparatus}

The apparatus Wave Exposer V20 (Samsung Inc, South Korea) was used and radiation powers were controlled from 1.6 to 4.0 SAR (specific absorption rate) by the selection switch on front panel.

\section{Short-term CDMA Exposure}

For the CDMA exposure experiment, mice were exposed to radiation at the brain with average SAR of $1.6 \mathrm{w} / \mathrm{kg}$ and $4.0 \mathrm{w} / \mathrm{kg}$ by using Wave Exposer V20 instrument. Exposure was conducted for regular one hour per day for five consecutive days for each group. Sham control group was also exposed to same experimental condition without any radiation. Individual animal's weight was recorded before and after exposure. Three hours after the last exposure in the fifth day, animals were anesthetized with diethyl ether and brains were collected using perfusion-fixation procedure with phosphate buffer saline (PBS) and 4\% para formaldehyde solution. The anesthesia was used to avoid animal stress and to lower the augmentation of blood pressure during perfusion, the fixation procedure.

\section{Immunohistochemistry \& Immunofluorescence}

Brains were removed from the skull post fixed in paraformaldehyde for 24 hours. Then brains' tissues were cryo protected in a series of sucrose solution $(10 \%, 20 \%, 30 \% \mathrm{w} / \mathrm{w})$ at $4^{\circ} \mathrm{C}$ until they sank.

Serial coronal section, $40 \mu \mathrm{m}$ were cut with freezing, sliding microtome and collected in wells. Immunohistochemistry was performed with free floating method. calbindin D-28k (Millipore) antibody was applied to brain sections at a final dilution of 1:5,000 in phosphate buffer saline based blocking buffer containing $1 \%$ bovine serum albumin, $0.3 \%$ Triton $\mathrm{X}-100$, and $1 \%$ normal horse serum. Sections were incubated for 48 hours at $4^{\circ} \mathrm{C}$. After three washes with phosphate buffer saline, sections were incubated with the respective secondary antibody at dilution ratio of $1: 250$ for 1.5 hours at the room temperature. Sections from each group were stained together to eliminate conflicts originating from different experimental conditions. Following additional washes, section were mounted on gelatin coated slides, dehydrated in ethanol, cleared in xylene, and cover slipped with DPX.

Analysis was performed under Olympus BX 51 microscope, a fluorescence microscope, and pictures of the sections were taken by a microscope digital camera system (DP50, Olympus, Japan). The NIH image program (Scion Image) was used to determine staining densities. The sum of the gray values of all pixels in a selected region was divided by the total number of pixels in the selected region to determine the mean density of immunoreactivity per unit area (mm-2).

Mathematically,

Mean Density $=$ Immunoreactivity/Area $(\mathrm{mm}-2)$

......................................Eq. 1

\section{Statistical Analysis}

For the statistical analysis, data were expressed in terms of mean $\pm \mathrm{SD}$ and were compared by unpaired student's t-test. Differences were considered significant when $\mathrm{p}<0.05$ at $95 \%$ confidence interval $(\mathrm{CI})$ of mean.

\section{RESULTS}

\section{Cerebellum}

The immunoreactivity for the cerebellum was observed in all three groups. Purkinje cells became darkly stained in all three groups with varying intensity. Dendrites could also be observed branching from the apical portion of the Purkinje cell into the molecular layer. However, axons of Purkinje cells were not stained at their proximal end. Only the distal portion of axons descending into the white matter was visible. The stellate and basket cells in the molecular layer and the granule 
and golgi cells in the granular layer remained unstained in all three groups (Figure.1).

Image analysis measurement illustrated the relative mean density of cerebellar IR in the molecular layer to be $146.65 \pm 0.09,138.47 \pm 0.078$, and $144.13 \pm$ 0.23 in low RF exposure, high RF exposure, and sham control groups respectively. The Purkinje layer's displayed $179.62 \pm 0.015,162.94 \pm 0.21$, and $158.60 \pm 0.045$ and granular layer's illustrated $91.42 \pm 0.02,75.46 \pm 0.08$, and $90.84 \pm 0.054$. Significant difference was observed in the granular layer between sham control and high RF exposure groups $(\mathrm{p}<0.005)$ (Figure 2).

Hippocampus: The mean number of labeled cells per unit length did not vary significantly between the three types in the CA1, CA2, and CA3 area of
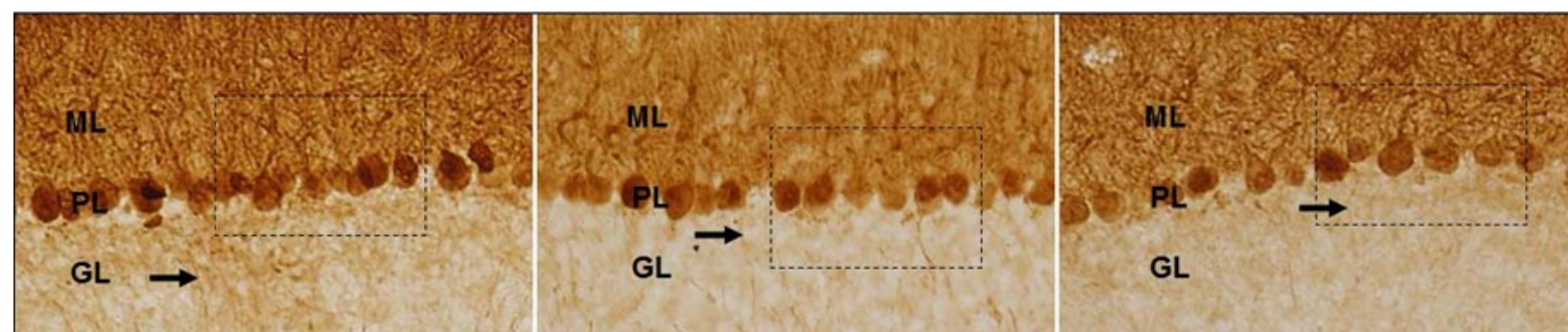

A

B

C GL
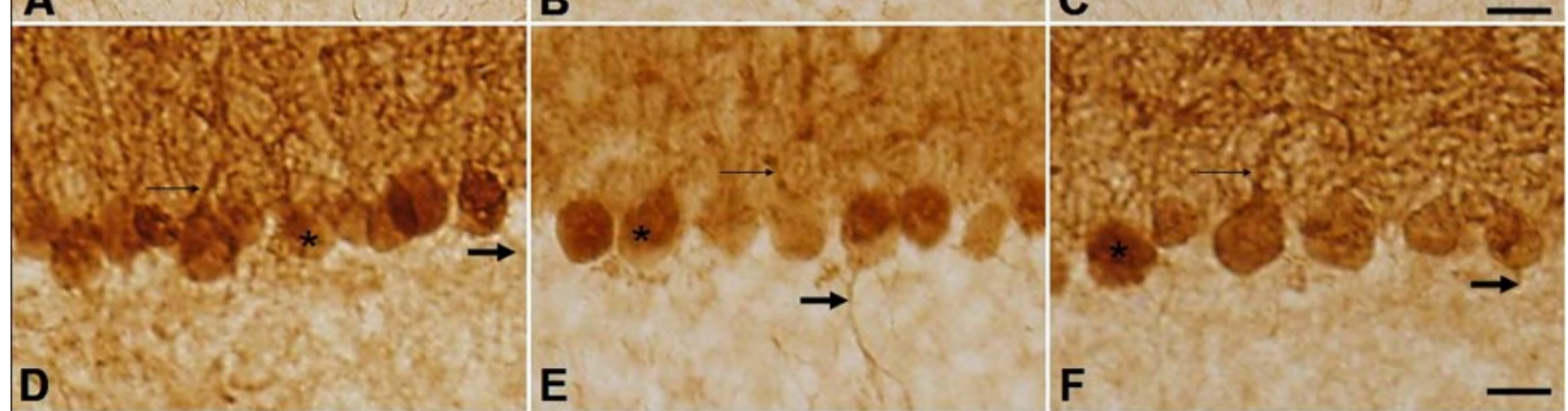

Figure 1: Calbindin D-28k immunoreactivity in the cerebellar cortex of low RF exposure (A, D), high RF exposure $(\mathrm{B}, \mathrm{E})$, and sham control (C, F) groups. Darkly stained Purkinje cells (asterisks) with dendrites (thin arrows) ascending into the molecular layer. Faint staining of axons (thick arrows) in all three groups.

Scale bar- $(\mathrm{A}, \mathrm{B}, \mathrm{C}=100 \mu \mathrm{m})(\mathrm{D}, \mathrm{E}, \mathrm{F}=20 \mu \mathrm{m})$

Abr: $\mathrm{ML}=$ Molecular Layer, $\mathrm{PL}=$ Purkinje Layer, $\mathrm{GL}=$ Granular Layer,

\section{Mean density of Calbindin D-28k in the cerebellar cortex}

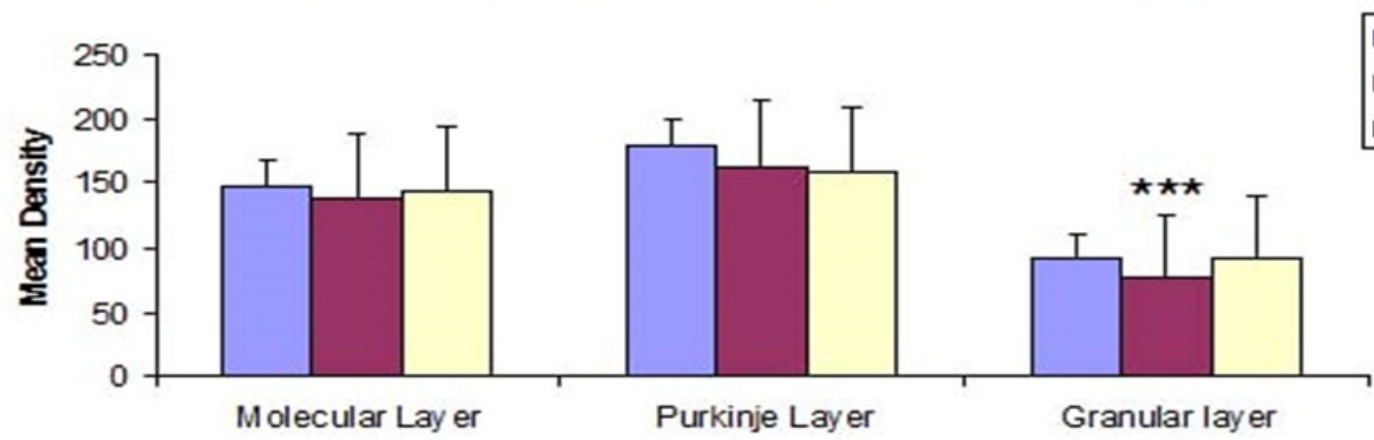

Figure 2: Image analysis of relative density of Calbinding-D28-K immunoreactivity changes in the cerebellar cortex of low RF exposure (A), high RF exposure (B), and sham control (C) groups. The data shown are mean \pm SD obtained from three different experiments.

$* * * \mathrm{p}<0.005$ 
the hippocampus. The signal was weakest in the CA3 region of the control group. The CA2 area of high RF exposure group was prominently labeled with calbindin D-28k. A highly ordered pattern of calbindin D-28k expression was observed in all three cornus ammunis areas of the hippocampus in all three groups. Images of dentate gyrus section immunostained against calbindin D-28k showed a homogenous pattern of intense immunoreactivity in all three layers of groups. All three layers of the dentate gyrus were well differentiated in all groups (Figure.5).

The statistical comparison revealed significant differences between sham control group (C) and


Figure 3: Calbindin D-28k immunoreactivity in the hippocampal region of low RF exposure (A, D), high RF exposure (B, E), and sham control (C, F) groups. Three regions (CA1, CA2, CA3) of the hippocampus margined along with the dentate gyrus (DG).

Scale bar-(A, B, C=100 $\mu \mathrm{m})$, Abr: $\mathrm{CA}=$ Cornu Ammonis

\section{Mean density of Calbindin D-28k in the hippocampal region}
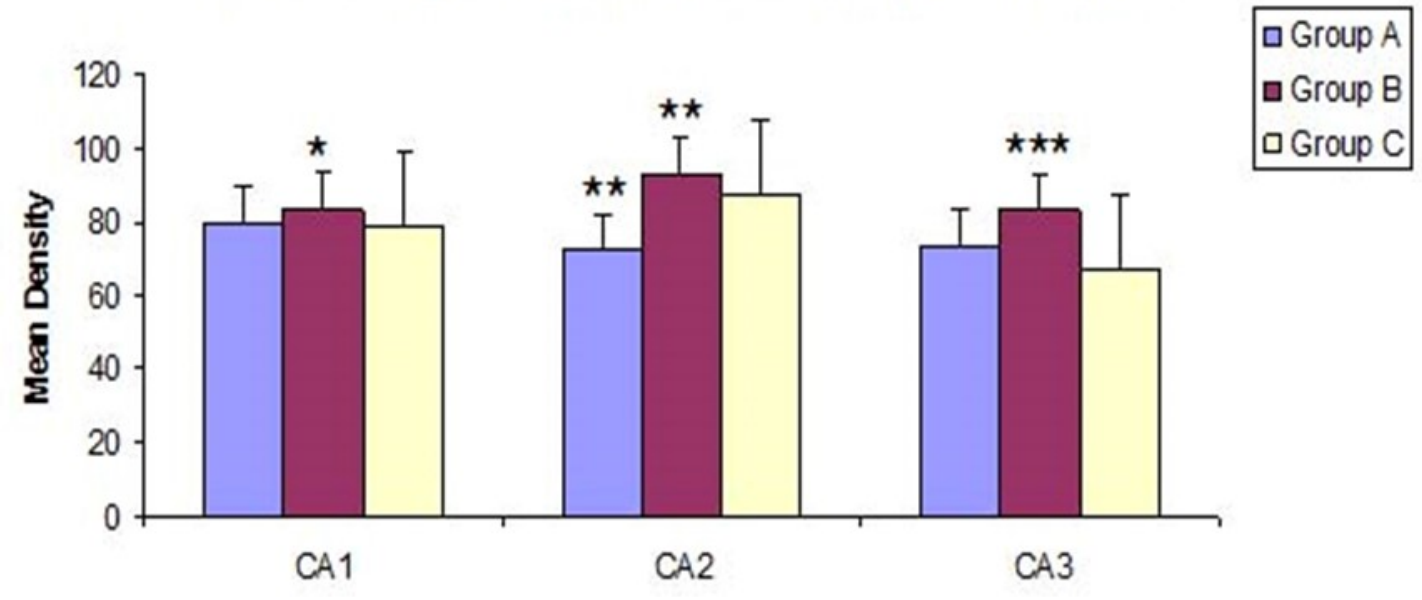

Figure 4: Image analysis of relative density of Calbinding-D28-K immunoreactivity changes in hippocampal region (CA1, CA2, CA3) of low RF exposure (A), high RF exposure (B), and sham control (C) groups. The data shown are mean $\pm \mathrm{SD}$ obtained from three different experiments. ${ }^{* *} \mathrm{p}<0.01,{ }^{* * *} \mathrm{p}<0.005$ 
high RF exposure group (B) $(p<0.0001)$ in the CA3 and between sham control group $(\mathrm{C})$ and low $\mathrm{RF}$ exposure group (A) in the $\mathrm{CA} 2$ area $(\mathrm{p}<0.005)$ (Fig.6).

\section{DISCUSSION}

The possible adverse interaction of radio-frequency electromagnetic fields (RF-EMFs) with living organisms presents an increasing concern nowadays. As per the claim of telecommunication companies, the increasing popularity of mobile phone may cover one billion populations by the year 2005. Because of their use in close vicinity to the brain, there is an always-high risk of central nervous system (CNS) problems. ${ }^{7,8,9}$ According to the previously documented studies, the adverse effect of mobile phones varies with the frequency of the radio wave, and can lead simple headache to brain tumors. Though the study conducted in USA failed to prove association of brain tumors, there is possibility of being damaged or even tumor, is high in temporal area at phone receiving side. ${ }^{10,11}$

The quantification of health hazards due to continuous exposure to microwave can be quantified using linear density of purkinje cells. ${ }^{12}$ The changes in cerebellar Purkinje cell stomata and dendritic arbors can be applied as the early marker for neuronal damage. Therefore, we investigated the effects of short-term exposure of RF radiation by evaluating calcium binding proteins and brain tumor marker in the mouse hippocampus and cerebellum.

Calbindin D-28k is a member of a large family of intracellular calcium binding proteins, containing EF-hand calcium binding motifs and related to calmodulin and troponin-C. Biological roles of Calbindin D-28k include calcium regulation and calcium-dependent signaling in neurons and during development. Calbindin antibody is often used as a marker for cerebellum Purkinje cells. Calbiding-D$28 \mathrm{~K}$ immunoreactivity displayed significant difference in the granular layer between sham control and high RF exposure groups and in the hippocampal region between sham control and high $\mathrm{RF}$ exposure groups in the $\mathrm{CA} 3$ and between sham control and low RF exposure groups in the CA2 area. This study showed that short-term exposure with radiofrequency radiation could induce disruption of calcium homeostasis by increasing calcium efflux and resulting neurobehavioral changes or brain tumor, which might related with known side effects.

\section{CONCLUSION}

This study showed that short-term exposure with radiofrequency radiation could induce disruption of calcium homeostasis by increasing calcium efflux and resulting neurobehavioral changes or brain tumor, which might related with known side effects.

\section{ACKNOWLEDGEMENT}

The author would like to thank Pharmacology Department, College of Medicine, Dankook University and IBST Center, South Korea for providing research facilities and fund.

\section{REFERENCES}

1. Kowalczuk CI, Robbins L, Thomas JM, and Saunders RD. Dominant lethal studies in male mice after exposure to a 50 $\mathrm{Hz}$ magnetic field, Mutation Research/Fundamental and Molecular Mechanisms of Mutagenesis. Elsevier Science B.V, 1995; 328: 229-237.

2. Sienkiewicz Z. Biological effects of electromagnetic fields and radiation. Journal of Radiological Protection, Chilton, England: National Radiological Protection Board, 1998.

3. Sienkiewicz Z. Deficits in spatial learning after exposure of mice to a $50 \mathrm{~Hz}$ magnetic field.Bioelectromagnetics, 1998;19:79-84. https://doi.org/10.1002/(SICI)1521-186X (1998)19:2<79::AID-BEM4>3.0.CO;2-0.

4. Moulder JE, Erdreich LS, Malyapa RS, Merritt J, Pickard WF, Vijayalaxmi. Cell phones and cancer: what is the evidence for a connection? Radiat Res. 1999;151:513531. https://doi.org/10.2307/3580028.

5. Hossmann KA,Hermann DM. Effects of electromagnetic radiation of mobile phones on the central nervous system. Bioelectromagnetics. 2003;24:49-62. https:// doi.org/10.1002/bem.10068. PMID: 12483665.

6. Adey WR. Tissue interactions with non-ionising electromagnetic fields. Physiol Revs. 1981;61:435-514. PMID: 7012860.

7. Thomas D. A comparison of fluorescent $\mathrm{Ca} 2+$ indicator properties and their use in measuring elementary and global signals. Cell Calcium. 2000;28:213-23. https:// doi.org/10.1054/ceca.2000.0152. PMID: 11032777 .

8. Moulder JE, Foster KR, Erdreich LS, McNamee JP. Mobile phones, mobile phone base stations and cancer: a review. Int J Radiat Biol. 2005;81:189-203. https:// doi.org/10.1080/09553000500091097. PMID: 16019928.

9. Ahlbom A, Green A, Kheifets L, Savitz D, Swerdlow A. Epidemiology of health effects of radiofrequency exposure. Environ Health Perspect. 2004;112:1741-54. https:// doi.org/10.1289/ehp.7306. PMID: 15579422 .

10. Inskip P D.How many people use wireless phones. Washington, D.C.: Cellular Telecommunication Industry Association. 2000;344:79-86.

11. Zook BC, Simmens SJ. The effects of pulsed $860 \mathrm{MHz}$ radiofrequency radiation on the promotion of neurogenic tumors in rats. Radiat Res. 2006;165:608-15. https:// doi.org/10.1667/RR3551.1. PMID: 16669743.

12. Hamblin DL, Wood AW, Croft RJ, Stough C. Examining the effects of electromagnetic fields emitted by GSM mobile phones on human event-related potentials and performance during an auditory task. Clinical Neurophysiology. 2004;115:171-8. https://doi.org/10.1016/ S1388-2457(03)00313-4. 